\title{
Eosinophilic esophagitis: a review
}

\author{
Elisa Ochfeld ${ }^{a}$ and Melanie Makhija ${ }^{b *}$
}

\begin{abstract}
Eosinophilic esophagitis is an antigen-mediated chronic disease that has been increasing in prevalence for the last few decades. A plethora of research has been done recently studying the pathophysiology and potential treatments for the disease. This review paper highlights the epidemiology, diagnosis, pathophysiology, and treatment of eosinophilic esophagitis including new diagnostic and treatment modalities for the disorder.
\end{abstract}

Statement of novelty: We review the epidemiology, diagnosis, pathophysiology, and treatment of eosinophilic esophagitis, and include new diagnostic and treatment modalities for the disorder.

\section{Introduction}

Eosinophilic esophagitis (EoE) is a chronic antigenmediated esophageal disease, which is characterized by symptoms of esophageal dysfunction and histologically is identified by eosinophil predominant inflammation. Landres et al. (1978) first described EoE in 1978 in a case report. EoE was distinguished from gastroesophageal reflux disease (GERD) in the 1990s, after the pathologic differences of eosinophil presence were identified and validated (Attwood et al. 1993). Cases prior to this were often misidentified as severe, treatment-refractory GERD, with complications such as strictures, mucosal tears, perforations, and esophageal rings. In the 1990s, it was also first noted that the symptoms and histologic changes of the esophagus related to EoE could be improved with the use of elemental formula, and thus that the pathology could be related to the ingestion of certain foods (Franciosi et al. 2009). Since the 1990s, there has been a significant increase in research and therefore understanding of EoE.

\section{Epidemiology}

EoE can occur at any age. Most cases occur in children, adolescents, and adults under the age of 50 (Dellon 2014). There is a male predominance and an increased prominence in Caucasians compared to other ethnicities. Males are affected 3-4 times more than females, and the reasons for this male predominance have yet to be identified. In 1 study, when adjusting for race as a confounding variable, the socioeconomic status and geographic characteristics of EoE patients were not found to be different than those of the general gastrointestinal (GI) clinic population (Franciosi et al. 2009). In this study of 335 children in the greater Philadelphia area with EoE, 83.6\% were Caucasian, compared with $70.9 \%$ of GI control subjects, $64.9 \%$ of allergy control subjects, and $73 \%$ of the greater Philadelphia population. About $75.8 \%$ of subjects were male, compared to $48 \%$ of GI control subjects, $60.4 \%$ of allergy control subjects, and $48 \%$ of the greater Philadelphia population (Franciosi et al. 2009). EoE has been identified in all continents with the exception
aPediatrics, Ann and Robert H. Lurie Children's Hospital of Chicago, Chicago, IL, USA; ' Allergy and Immunology, Ann and Robert H. Lurie Children's Hospital of Chicago, Chicago, IL, USA
Submitted 31 October 2017

Accepted 28 November 2017

Available online 30 November 2017

LymphoSign Journal 4:119-135 (2017)

dx.doi.org/10.14785/lymphosign-2017-0012 
of Africa (Dellon 2014; Akhondi 2017), and is reported more frequently in Western countries than in Asia (Dellon 2014). There are also environmental and geographic patterns. EoE varies by climate zone, with cold and arid climates having higher rates of EoE (Hurrell et al. 2012). Other studies show that EoE is more common in rural areas with low population density (Spergel et al. 2011; Jensen et al. 2014).

There is a strong association between EoE and atopic disease, and it is more commonly diagnosed in those with a strong personal or family history of atopy. An estimated $26 \%-86 \%$ of adults and $42 \%-93 \%$ of children diagnosed with EoE also have another allergic condition (Ishihara et al. 2016). Family history of EoE is present in $7 \%$ of cases (Akhondi 2017). If 1 child has a diagnosis of EoE, their sibling has a 50\% increase of being affected compared to the general population. Family studies performed by Alexander et al. (2014) reveal high heritability in nuclear families (72.0\%). When analyzing monozygotic and dizygotic twins, a 58\% proband concordance was found in identical twins whereas dizygotic twins have a $36 \%$ concordance compared to non-twin siblings, indicating that shared environmental factors strongly contribute as well (Alexander et al. 2014). Risk also increases with the severity of the sibling's disease (for example, advanced stenotic disease) (Akhondi 2017).

Prevalence helps to measure burden of disease and varies based on the population that is studied. In EoE, prevalence is also affected by the timing of the study and is dependent on if it was conducted before or after the discovery of proton pump inhibitor (PPI)responsive esophageal eosinophilia (PPI-REE) (Liacouras et al. 2011; Dellon et al. 2013a). EoE prevalence is estimated to be highest in the US, Western Europe, and Australia, compared to Japan or China (Dellon 2014; Dellon et al. 2014). In a large US study with data from 2009 to 2011, prevalence of EoE was estimated at 56.7/100 000 persons (Dellon et al. 2014). An epidemiologic review of EoE from 2014 demonstrated prevalence in the general population to be approximately $0.5-1$ per 1000 (Dellon 2014), with most estimates in the US ranging from 40 to 90 cases per 100000 (Dellon 2014). These estimates of prevalence in the US were found to be consistent with prevalence data from Australia (89/100 000), Switzerland $(43 / 100000)$, Spain (45/100 000), and Canada (34/100 000) (Dellon 2014). The prevalence of EoE seems to increase with age until a peak occurs at age $35-45$, and then prevalence decreases, which is not an expected observation for a chronic and non-fatal disease (Dellon 2014; Dellon et al. 2014).

When looking at the specific population of patients undergoing endoscopy, the prevalence of EoE is quite high. A prospective study that collected esophageal biopsies in adult patients undergoing outpatient upper endoscopy for any indication found that $6.5 \%$ of patients had a diagnosis of EoE (Veerappan et al. 2009). In this study, EoE patients were more likely to be male ( $80 \%$ vs. $48 \%$ of those without EoE), under 50 years of age ( $72 \%$ vs. $48.9 \%$ ), have asthma (32\% vs. $10.8 \%)$, present with food impaction ( $32 \%$ vs. $8.9 \%)$, have dysphagia ( $64 \%$ vs. $38.1 \%$ ) and were more likely to have classic endoscopic findings of EoE (rings, furrows, plaques, strictures, etc.) (Veerappan et al. 2009). In patients undergoing endoscopy for symptoms of dysphagia, the prevalence is higher at $12 \%-23 \%$ (Prasad et al. 2007; Mackenzie et al. 2008; Ricker et al. 2011; Sperry et al. 2011; Dellon et al. 2013b). In 1 study, the prevalence of EoE in patients undergoing endoscopy after a PPI trial for symptoms of dysphagia was found to be $23 \%$ (Dellon et al. 2013b), whereas $14 \%$ of patients had PPI-REE (Dellon et al. 2013b). In another study of 222 patients with dysphagia undergoing endoscopy with biopsy, 15\% were found to have EoE (Prasad et al. 2007). In patients presenting to the emergency department with food impaction, EoE is the most common etiology identified, with $46 \%-63 \%$ of these patients ultimately receiving the diagnosis of EoE (Sperry et al. 2011). Physicians should have a high degree of suspicion for EoE in patients undergoing endoscopy for any reason, and should strongly consider obtaining biopsies to properly evaluate for this condition. Currently, the guidelines in place recommend obtaining biopsies for all patients presenting with unexplained dysphagia, even if the esophagus on upper endoscopy looks grossly normal or a cause of dysphagia other than EoE is identified (Liacouras et al. 2011; Dellon et al. 2013a).

The incidence of EoE is approximately 1/10 000 new cases per year, and has been increasing for the last 10-20 years (Dellon 2014). Increasing EoE incidence has been identified in the United States, Switzerland, and the Netherlands (Okada et al. 2010; Hruz et al. 2011). The number of new cases could be rising for a multitude of reasons. All allergic diseases including 
asthma, atopic dermatitis, allergic rhinitis, and food allergies have been increasing in recent decades (Okada et al. 2010). The incidence of EoE, as an allergen/immune related disorder, would be expected to rise in parallel with these other allergic diseases. Another explanation for the rise of EoE incidence and prevalence is increasing recognition. Medical practitioners are more aware of this diagnosis and thus more biopsies during endoscopy are performed to assess for the condition. This, however, only partially explains the increase.

There are many hypotheses that aim to explain the increasing incidence of EoE, including changes in food allergens, aeroallergens, increase in PPI use, decrease in Helicobacter pylori colonization, and early life exposures (Dellon 2014). Certain foods have long been understood to be triggers of EoE, but it is unknown why foods that were tolerated for so long are now common offending agents. Potential contributors include changes in agricultural practice such as increasing pesticide, antibiotic, and hormone use. With regard to aeroallergens, EoE is more commonly diagnosed in the summer and fall, seasons with higher aeroallergen activity (Prasad et al. 2009). Another factor could be the decrease in $H$. pylori colonization, occurring since the 1990s. In a large cross-sectional analysis using over 165000 patients, there was an inverse relationship between $H$. pylori colonization and EoE diagnosis on biopsy (Dellon et al. 2011). Additionally, the use of PPIs has increased over the last 30 years and may play a role in EoE incidence. PPI use can increase the permeability of the upper GI tract, creating new routes of antigen exposure and may be associated with the development of new food specific antibodies (Mullin et al. 2008; Merwat and Spechler 2009). However, it is also well known that PPI use can significantly reduce eosinophils in PPI responsive disease. A PPI trial is now the first line in the treatment algorithm for EoE (Figure 1).

Early life exposures may also be important in the development of EoE, and may be contributing to the increasing incidence. One study showed that infants who received antibiotics were 6 times more likely to develop pediatric EoE than controls with no antibiotic exposure in infancy (confidence interval: 1.7-20.8) (Jensen et al. 2013). This study also showed an increased risk of EoE in those delivered by cesarean section, premature infants and those who were nonexclusively breast-fed (Jensen et al. 2013). More research is required to fully elucidate and differentiate the variables thought to be contributing to rising rates of EoE.

\section{Pathophysiology}

Evidence suggests a strong familial association in EoE although inheritance seems to be non-Mendelian (Noel et al. 2004). Several candidate genes that likely contribute to the development of EoE have been identified using genome-wide association studies (GWAS) and candidate-gene identification. These genes include thymic stromal lymphopoietin (TSLP), periostin (POSTN), calpain 14 (CAPN14), desmoglein 1 (DSG1), EMSY, LRRC32, STAT6, ANKRD27, and FLG (O'Shea et al. 2017).

The EoE transcriptome is a term that was coined by Blanchard et al. (2006). This is a group of 574 dysregulated genes, which help differentiate EoE patients from healthy controls and from patients with noneosinophilic esophagitis. The EoE transcriptome is highly conserved across age, gender, atopy, and non-familial relationship. A screening tool developed using 94 genes from the transcriptome may become a diagnostic tool to help differentiate patients with EoE from those with other forms of esophagitis, as well as helping distinguish patients with active EoE from those in remission (Wen et al. 2013). The largest numbers of transcriptional changes in the EoE transcriptome occur at 1q21, a region that contains genes involved in squamous epithelia cell differentiation including Filaggrin. These genes are down regulated in EoE consistent with impaired barrier function (Sherrill et al. 2014; O'Shea et al. 2017; Rochman et al. 2017). The Chemokine ligand 26 (CCL26) or eotaxin-3 gene is the most highly up-regulated gene (53-fold) in the EoE transcriptome (Blanchard et al. 2006). CCL26 is thought to be the main driver for eosinophil recruitment into the esophagus. Levels of CCL26 correlate significantly with esophageal eosinophil and mast cell levels (O'Shea et al. 2017). Another up-regulated gene in the transcriptome is POSTN. $P O S T N$ is involved in regulating cell migration and adhesion. POSTN promotes allergic inflammatory responses in the lung and esophagus. It may also induce expression of TSLP (Blanchard et al. 2008; Masuoka et al. 2012). Other important genes include STAT6, a gene important for Th2 development; $L R R C 32$, a TGF $\beta$ binding protein; and EMSY, which is involved in transcriptional regulation (O'Shea et al. 2017). 


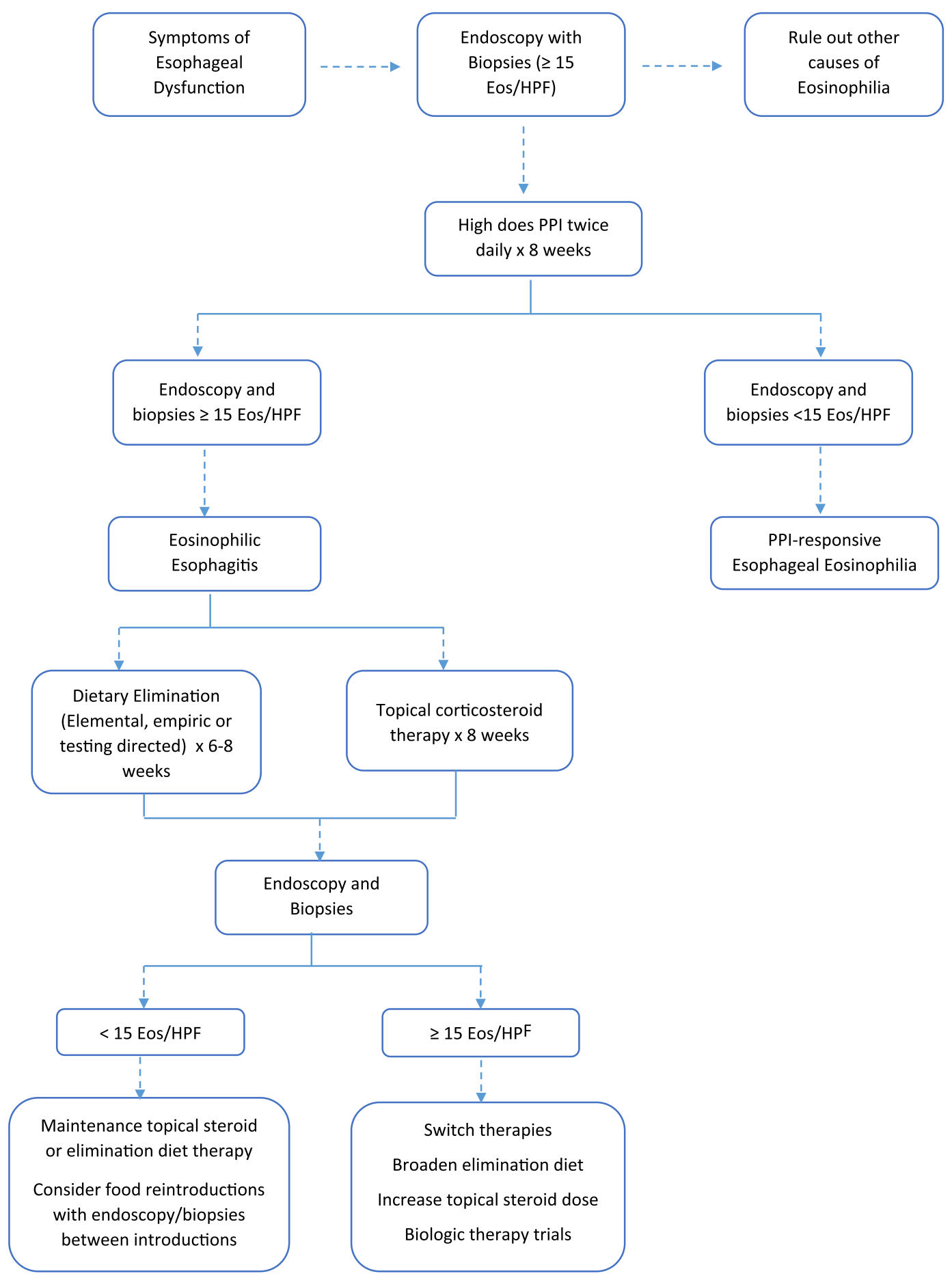

Figure 1: Diagnostic and treatment algorithm for the management of eosinophilic esophagitis.

Together these genes promote development of eosinophilic inflammation of the esophagus.

A GWAS study of 351 patients with EoE and 3104 controls was genotyped for 550000 variants. A single locus on chromosome $5 \mathrm{q} 22$ spanning TSLP was associated with EoE susceptibility (Rothenberg et al. 2010).
TSLP encodes a Th2 promoting cytokine involved in allergic disease. It is released by activated epithelial cells and promotes Th2 differentiation (Gudbjartsson et al. 2009). CAPN14 is a gene that encodes a proteolytic enzyme specific to the esophagus, which is induced by interleukin (IL)-13 (Litosh et al. 2017). Unlike TSLP, which is associated with multiple allergic diseases, 
CAPN14 may be specific to the esophagus and EOE. CAPN14 is overexpressed in esophageal epithelial cells resulting in diminished barrier function (Litosh et al. 2017). Another important gene is DSG1, which encodes a transmembrane protein that is down regulated in esophageal mucosa of patients with active disease. The protein's main role is to maintain epithelial integrity through calcium-dependent intercellular adhesion. Down-regulation of DSG1 is mediated by IL-13. Although the role of impaired barrier function in EoE is not completely understood, barrier abnormalities may provide an entry pathway for allergens and induce systemic allergen sensitization (O'Regan et al. 2008).

Th2 cytokines important in the development of EoE include IL-5 and IL-13. IL-5 drives mucosal esophageal eosinophilia and may potentiate tissue remodeling (O'Shea et al. 2017). IL-13 is secreted mainly by activated Th2 cells and is critical for eosinophil survival, activation, and recruitment. IL-13 contributes to eosinophilic chemotaxis and induces eotaxin-3. IL-13 also induces tissue remodeling and disruption of the epithelial barrier. In EoE, the esophagus expresses elevated levels of IL-13 (O'Shea et al. 2017). Evidence suggests that IgE does not have a prominent role in the pathogenesis of EoE. A clinical trial looking at omalizumab, a humanized monoclonal anti-IgE antibody, as a treatment for EoE showed no histological or symptomatic improvement in those on active treatment compared to controls (Clayton et al. 2014). Immunoglobulin (Ig) $\mathrm{G}_{4}$ in tissue may play a role in the pathogenesis of EoE. In this same trial, mucosal biopsies of adults with active EoE revealed a 45-fold increase in $\mathrm{IgG}_{4}$ staining compared to controls (Clayton et al. 2014). The role of $\mathrm{IgG}_{4}$ in EoE continues to be studied.

Microbial imbalance may also contribute to EoE. Early life exposures such as cesarean section delivery and antibiotic use in infancy may increase the risk of EoE later in life (Radano et al. 2014). This may be related to microbial imbalance and Th2 skewing of the immune system. A prospective study of children and adults with EoE found that subjects with EoE had a higher bacterial load in esophageal mucosal secretions compared to controls regardless of treatment stage (Harris et al. 2015). In addition, several centers have noted an inverse relationship between H. pylori infection and EoE. This may have to do with skewing the immune system towards a Th1 milieu in $H$. pylori infection and Th2 environment when H. pylori is lacking (Dellon et al. 2011; von Arnim et al. 2016; O'Shea et al. 2017; Sonnenberg et al. 2017). The exact pathogenic mechanism that microbes may contribute to the development of EoE remains to be determined.

\section{Clinical presentation}

There are no pathognomonic presenting features of EoE. The most common presenting symptom in adults is solid food dysphagia (Kapel et al. 2008; Liacouras et al. 2011; Akhondi 2017). Other common presenting symptoms in adults include food impaction, atypical chest pain, emesis, and epigastric pain. In children, the common presenting symptoms are abdominal pain, food refusal, recurrent emesis, poor growth, and weight loss (Akhondi 2017). Infants and toddlers often present with feeding difficulties, food refusal, and failure to thrive (Aceves et al. 2009; Mukkada et al. 2010; Liacouras et al. 2011). School-aged children often present with emesis or abdominal pain (O'Regan et al. 2008; Liacouras et al. 2011). Dysphagia is the most common presenting symptom in adolescents (Liacouras et al. 2011). Another frequent presenting symptom is food impaction requiring endoscopic removal, which occurs in $33 \%-54 \%$ of adults with EoE (Aceves et al. 2009; Liacouras et al. 2011). History is often extremely useful, and attention should be dedicated to the patient's swallowing, chewing, and eating habits. Often these patients have adapted mechanisms such as eating abnormally slowly, taking small bites, cutting food into small pieces, and drinking excessive amounts of water with meals to reduce dysphagia symptoms. Patients may also cope by avoiding textured or bulky foods. In many cases of EoE in both adults and children, the physical exam is within normal limits until late in the disease process.

History of atopy is critical, and can help point the clinician to a diagnosis of EoE in both adults and children. Approximately $75 \%$ of people with EoE have a history of atopy (Akhondi 2017), and thus any co-morbid allergic diseases should be identified. In pediatric patients, it is crucial to evaluate the growth chart, as growth failure and weight loss are common presenting symptoms for EoE. There are no oral or pharyngeal manifestations of EoE that are visible on examination (Liacouras et al. 2011). 
PPI-REE is an important subgroup of EoE. Patients with PPI-REE tend to have symptoms of esophageal dysfunction and have had GERD diagnostically excluded, but demonstrate clinicopathologic response to PPIs, with improvement in symptoms and eosinophilia of the esophagus after PPI therapy (Liacouras et al. 2011; Molina-Infante et al. 2011). It is not clear exactly why PPIs assist with the condition in these individuals. Proposed mechanisms include PPI-induced healing of the epithelial barrier, decreased eosinophil lifespan, and anti-inflammatory properties of PPIs (Kedika et al. 2009; Liacouras et al. 2011). Many prospective studies have shown that $30 \%-40 \%$ of adults with EoE in fact have PPI-REE (Molina-Infante and Katzka 2014).

A thorough allergic evaluation is necessary in patients undergoing a work-up or who have received a diagnosis of EoE. Using data from multiple studies, it is estimated that $28 \%-86 \%$ of adults and $42 \%-93 \%$ of pediatric patients with EoE have another allergic disease (Roy-Ghanta et al. 2008; Spergel et al. 2009; Erwin et al. 2010; Liacouras et al. 2011). Comorbid atopic conditions include asthma, IgE-mediated food allergies, atopic dermatitis, and allergic rhinitis. Many patients with EoE have a sensitization to food allergens and (or) aeroallergens based on skin prick testing or specific IgE testing (Liacouras et al. 2011). It is estimated that the rate of IgE mediated food hypersensitivity in patients with EoE ranges from 15\% to 43\% (Liacouras et al. 2011). Higher rates of food-induced anaphylaxis can occur in patients with EoE (Sugnanam et al. 2007; Liacouras et al. 2011). Serum food-specific IgE levels and skin prick testing for foods may be helpful to identify comorbid disease. These tests may also be useful as patients with sensitization may develop IgE-mediated allergy to foods they were previously consuming if a prolonged elimination occurs as part of their treatment. Interestingly, cow's milk protein is the food implicated in all of the case reports to date of patients developing IgE-mediated allergy after elimination diet for EoE (Hill et al. 2015; Alsalamah et al. 2016; Soller et al. 2017). Cow's milk protein is the most common trigger of EoE (Kagalwalla et al. 2011), therefore, it is the most common food eliminated from the diet of patients with EoE. Other than frequency of elimination, the reasons for this association between elimination of cow's milk protein for EoE and the development of IgE mediated allergy are not fully understood. Environmental triggers have been found in experimental models of EoE
(Mishra et al. 2001; Rayapudi et al. 2010). As many studies have documented aeroallergen sensitization and seasonal variability in patients with EoE, EoE patients should also be evaluated for aeroallergen sensitization (Liacouras et al. 2011).

Esophageal eosinophilia can be present in disease pathologies other than EoE. It is important to have a differential diagnosis, to distinguish EoE from other illnesses. Other diseases that can cause esophageal eosinophilia include GERD, infectious processes, and systemic diseases. GERD should respond to high-dose PPI therapy. PH monitoring can also be performed to rule out GERD. Parasites and fungal infections that cause elevated eosinophil counts will often be positive on specific laboratory tests and respond to tailored treatment, and eosinophils will often be found beyond the esophagus and in the periphery. Hyper-eosinophilic syndromes will have systemic findings and peripheral eosinophilia. Systemic diseases will have other organ system involvement, including Crohn's disease, celiac disease, vasculitis, connective tissue disorders, and other rheumatologic and dermatologic conditions. Drug reactions should show improvement of symptoms and histology after the offending medication is removed (Akhondi 2017).

\section{Diagnosis}

EoE is a clinicopathologic condition that requires symptoms of esophageal dysfunction, and an esophageal biopsy showing eosinophil-predominant inflammation in 1 or more biopsy specimens (with a minimum threshold of 15 eosinophils per at least 1 high power field) (Liacouras et al. 2011; Akhondi 2017). The disease must be isolated to the esophagus. EoE is a diagnosis of exclusion, and therefore other causes of esophageal eosinophilia must be excluded before the diagnosis can be made.

Patients often have years of persistent or intermittent symptoms prior to an official diagnosis (Akhondi 2017). It is crucial to perform a detailed history and physical examination, and if EoE is suspected, proceed with endoscopy with biopsy. Laboratory testing is often performed but is not required for diagnosis, and is frequently not useful in making the diagnosis.

With regard to laboratory studies, patients with EoE can have elevated inflammatory markers and an 
elevated serum IgE, though these findings are nonspecific. A complete blood count will typically show a normal peripheral eosinophil count (Akhondi 2017). However, some studies have shown increased peripheral eosinophilia in patients with EoE. In 1 study, $40 \%-50 \%$ of patients had an increase in circulating peripheral eosinophils (over 300-350 per $\mathrm{mm}^{3}$ ) (Aceves et al. 2007; Dellon et al. 2009; Liacouras et al. 2011). Total serum IgE levels have been found to be increased in $50 \%-60 \%$ of patients with EoE however there is little evidence to support measuring $\operatorname{IgE}$ as a marker of disease or inflammation in these patients (Roy-Ghanta et al. 2008; Erwin et al. 2010; Liacouras et al. 2011). Patients with EoE can have increased levels of IL-5, IL-13, and IL-15, though there is not enough evidence to endorse measuring these levels arbitrarily in the work-up or management of EoE (Liacouras et al. 2011). Currently, there is not enough evidence to support the use of any single inflammatory marker as an indicator of disease in patients with EoE (Liacouras et al. 2011).

Endoscopy with esophageal biopsy is the only reliable diagnostic test for EoE (Liacouras et al. 2011). On endoscopy, there are many features that can be visible in EoE, including linear longitudinal furrows (seen in $48 \%$ of patients in 1 study), stacked circular rings (44\%), attenuation of the sub-epithelial pattern (41\%), eosinophil micro-abscesses or whitish plaques (27\%), strictures $(21 \%)$, and esophageal narrowing (9\%) (Akhondi 2017; Bonis and Furuta 2017). In extreme cases, mucosal lacerations or perforations of the esophagus are identified (Akhondi 2017; Bonis and Furuta 2017). One can also find fixed esophageal rings (corrugated rings or trachealization), transient esophageal rings (feline folds or felinization), edema, diffuse esophageal narrowing, a narrow caliber esophagus or evidence of mucosal fragility (crepe-paper appearance) (Liacouras et al. 2011). The sensitivity of these endoscopic findings is low, but their specificity is high. In 1 study, it was found that the specificity for a diagnosis of EoE was $91 \%$ for the presence of esophageal rings, $94 \%$ for whitish plaques, and $95 \%$ for linear furrows and strictures (Akhondi 2017). However, because all of these endoscopic features can be seen in other disorders as well as EoE, none are pathognomonic for the condition (Liacouras et al. 2011). There are 2 subtypes of EoE, which are characterized based on endoscopic findings: inflammatory EoE and fibrostenotic EoE. Inflammatory EoE is more common in pediatric patients, and will often show transient esophageal rings, furrows, and plaques. Fibrostenotic EoE more commonly presents with fixed rings and strictures (Akhondi 2017).

Biopsy in EoE reveals eosinophil-predominant inflammation in at least 1 biopsy site, with a minimum threshold of 15 eosinophils per at least 1 high power field. There is not enough evidence to confirm that elevated levels of eosinophils per high power field correlate with higher levels of disease severity (Pentiuk et al. 2009; Liacouras et al. 2011). Eosinophils should be confined to the esophagus, and not extend to the stomach or more distal portions of the GI tract. To establish the diagnosis, patients should undergo a PPI trial for 8 weeks prior to biopsy, to evaluate if the eosinophilia is persistent despite PPI therapy (and thus ruling out GERD and PPI-REE).

Esophageal biopsy should be performed by obtaining 2-4 biopsies from the distal esophagus and 2-4 biopsies from the proximal and midsection of the esophagus (Akhondi 2017). EoE distribution is often not consistent and is variable between esophageal segments, thus multiple biopsies from each site are necessary to make the diagnosis. It is common to obtain gastric antrum and duodenal biopsies, to rule out eosinophilia in these locations (Liacouras et al. 2011; Akhondi 2017). Per the diagnostic EoE guidelines updated in 2011, it is recommended that gastric and duodenal biopsy specimens be obtained in all children being evaluated for EoE (due to more difficult symptom identification), and for clinicians to use their discretion in adult patients (Liacouras et al. 2011).

Pathologists assessing the biopsy specimens should report all abnormalities visualized, including peak eosinophil values (from the area with the highest density of eosinophils), eosinophilic micro-abscesses, extracellular eosinophil granules, surface layering of eosinophils, basal cell hyperplasia, dilated intercellular spaces, and lamina propria fibrosis (Liacouras et al. 2011). It is critical to acknowledge that many patients with EoE have normal endoscopic findings, and thus EoE diagnosis is confirmed by biopsy histopathology and symptomatology. In 1 study, 9.8\% of 102 patients with a normal endoscopic evaluation had histologic evidence of EoE (Prasad et al. 2007; Liacouras et al. 2011). The sensitivity of biopsy increases as the number of biopsy sites increases. One study showed that by using 
the threshold of 15 eosinophils per high power field for diagnosis, there was a diagnostic sensitivity of $84 \%$, $97 \%$, and $100 \%$ for obtaining 2, 3, and 6 biopsy specimens respectively (Shah et al. 2009; Liacouras et al. 2011). This supports obtaining more biopsy specimens to promote diagnostic accuracy. Another consideration regarding diagnosis of EoE is the limitation of using a high-powered field (HPF) approach to diagnosis. This is because there is lack of standardization regarding the size of an HPF, and thus the histologic findings may vary based on the interpreter/pathologist. There is also debate as to the utility of barium contrast radiography in EoE. While it may be helpful in patients with strictures, 1 study showed that barium contrast radiography was normal in $12 / 17$ children with EoE (Binkovitz et al. 2010; Liacouras et al. 2011). Barium contrast studies are not part of the routine diagnostic workup for EoE.

Diagnostic modalities for esophageal disorders including EoE, other than endoscopy, are being studied. One of these modalities is the esophageal string test (EST). For the EST, the patient swallows a capsule with nylon string attached to one end. Luminal secretions from the proximal string are evaluated for eosinophilderived proteins, including eosinophil-derived neurotoxin, eosinophil cationic protein, eosinophil peroxidase, major basic protein 1, and charcot-leyden crystal protein (Furuta et al. 2013). In 1 study, ESTs were performed in 41 children with active EoE, 8 patients with treated EoE in remission, 4 with GERD, and 15 normal controls (Furuta et al. 2013). EST secretions and endoscopic biopsy samples were evaluated. It was found that EST measured eosinophilderived protein biomarkers significantly distinguished children with active EoE from those with EoE in remission, those with GERD and controls. Additionally, the level of eosinophil-derived proteins found on EST significantly correlated with peak and mean eosinophils per HPF in the esophagus (Furuta et al. 2013).

Another diagnostic modality being studied is the Cytosponge. The Cytosponge is an ingestible gelatin capsule with compressed mesh attached to a string. In 1 study, 20 adults with EoE were assessed with the Cytosponge and then with endoscopy and biopsies (Katzka et al. 2015). All of the subjects in this study had dysphagia; 15 had strictures and 13 had active disease. Cytosponge evaluation was able to correctly identify $11 / 13$ patients with active EoE. $57 \%$ specificity was found, with the Cytosponge testing correctly identifying 4 of the 7 patients without active disease. All patients preferred Cytosponge as a diagnostic modality, compared to endoscopy with biopsy (Katzka et al. 2015). More information and larger controlled studies are required to further elucidate whether these newer methods are reliable diagnostic tools for EoE.

\section{Treatment}

The goal of EoE treatment is to improve both clinical symptoms and number of eosinophils obtained on histologic specimens to obtain complete remission of the disease. Symptomatic treatment is not enough to define regression of disease. A multi-center series of $269 \mathrm{EoE}$ patients found significant discrepancy between the presence of symptoms and histological response to drug therapy (Safroneeva et al. 2016). Endoscopy and histologic follow up is recommended, however, the 15 eosinophils/HPF cut-off is sometimes arbitrary and clinical judgment needs to be used to interpret borderline eosinophil counts.

The first line of therapy for all EoE is PPI treatment for at least 8 weeks. A subgroup of patients who present with clinical and histological findings of EoE will respond to PPI therapy with complete resolution of their disease (Liacouras et al. 2011). In addition to PPI therapy, current treatment options for EoE include dietary elimination therapy, swallowed (topical) corticosteroids, and esophageal dilations. Possible biologic therapies are being studied (Table 1).

The 3 main types of dietary therapy include elemental diet, allergy test-directed elimination, and empiric

\section{Table 1: Current and emerging therapies for the treatment of eosinophilic esophagitis.}

\begin{tabular}{ll}
\hline $\begin{array}{l}\text { Current therapies } \\
\text { Topical corticosteroids }\end{array}$ & $\begin{array}{l}\text { Budesonide } \\
\text { Fluticasone propionate }\end{array}$ \\
\hline Dietary therapies & $\begin{array}{l}\text { Elemental diet } \\
\text { Elimination diets }\end{array}$ \\
\hline Esophageal dilation & - \\
\hline Emerging therapies & Mepolizumab \\
\hline Anti-IL-5 antibody & Reslizumab \\
\hline Anti-IL-13 antibody & QAX576 \\
\hline Anti-IL-4R $\alpha$ antibody & Duplizumab \\
\hline CRTH2 inhibitor & OC000459 \\
\hline Anti-IL-5R $\alpha$ & Benralizumab \\
\hline
\end{tabular}


elimination diets. Elemental diet is the most effective form of therapy with remission rates of $>90 \%$ having been described in both children and adults (Markowitz et al. 2003; Peterson et al. 2013; Arias et al. 2014). This diet involves eliminating all foods and consuming only an amino acid-based, elemental formula (amino acids, carbohydrates, and medium chain triglycerides). Barriers to this dietary therapy include poor taste, monotony, and high cost along with the social isolation that is felt from not eating regular foods. Occasionally, 1 or 2 solid foods are added for this reason. This diet is useful in children who have failure to thrive and feeding difficulties or when patients are refractory to other therapies. Gastric tube placement may be necessary in order for patients to receive adequate nutrition. Very few adults accept this form of therapy (Peterson et al. 2013).

Empiric elimination diets involve elimination of common IgE-mediated allergic foods. There is some variation in terms of which foods are eliminated depending on location. The first empiric elimination diet studied was the 6-food elimination diet (SFED). This diet includes removal of cow's milk, egg, wheat, soy, nuts (peanut and tree nuts), and seafood (fish and shellfish) from the patients' diet. The first SFED study demonstrated histological remission in $74 \%$ of children (Kagalwalla et al. 2006). Other studies in both children and adults treated with the SFED have demonstrated remission rates of $72 \%-74 \%$. Subsequent food reintroduction after SFED has identified cow's milk, wheat, egg, and soy as the 4 foods most likely to induce disease recurrence (Kagalwalla et al. 2011; Henderson et al. 2012; Spergel et al. 2012a). Given this knowledge, a multi-center prospective study of a 4 -food elimination diet (4-FED) was done. In this study, subjects eliminated cow's milk, egg, soy, and wheat from their diet. This study demonstrated an efficacy of $64 \%$ in children with clinical and visual improvement on endoscopy in $91 \%$ and $93 \%$, respectively (Kagalwalla et al. 2017). Since cow's milk has been found to be the most common trigger food, and much easier to avoid than multiple foods, a cow's milk only elimination diet has been studied and seems to be effective in $50 \%-65 \%$ of patients (Kagalwalla et al. 2012; Kruszewski et al. 2016). Cow's milk elimination is complicated as conformational epitopes of cow's milk protein change with heating. A small retrospective study of 15 patients with cow's milk protein-induced EoE found that 11 (73\%) maintained histologic remission despite consuming baked milk products regularly for 6 weeks. Further prospective study is needed to validate whether this can be generalized (Leung et al. 2013).

The last form of dietary therapy is test-directed elimination. This consists of avoidance of foods that test positive on allergy testing. A 2006 study found that using a combination of skin prick and atopic patch test results to identify foods for elimination demonstrated remission in $72 \%$ of children (Spergel et al. 2007). Subsequent studies in both children and adults have failed to replicate these results (Moawad et al. 2016; Philpott et al. 2016).

The goal of dietary therapy is to gradually reintroduce foods one at a time with histological and clinical assessment in between introductions, with a long-term goal of avoiding the minimal amount of foods to keep the disease in remission (Kagalwalla et al. 2011). All dietary therapies are performed for at least 6-8 weeks after which another endoscopy with biopsies is performed. If histological and clinical remission has been induced, foods will be reintroduced either one at a time or in groups (i.e., fruit, meats, etc.). Each food reintroduction lasts 6-8 weeks followed by repeat endoscopy with biopsies, as well as clinical assessment of symptoms between introductions (Kagalwalla et al. 2011).

Topical steroids are the other first-line option for the treatment of EoE. They have been shown to induce histological remission and symptom improvement. After 8 weeks of topical steroid therapy, a repeat endoscopy with biopsies is performed to assess response to therapy. The topical steroid formulations used were originally designed for patients with asthma and were not intended for esophageal disease (Moawad et al. 2016). Budesonide and fluticasone are the 2 medications that have been studied for EoE. Swallowed fluticasone in doses of $440 \mu \mathrm{g}$ twice-daily to $880 \mu \mathrm{g}$ twice-daily has been studied in 3 placebo controlled, randomized controlled trials. Response rates range from $50 \%$ to $65 \%$ in children and adults (Konikoff et al. 2006; Alexander et al. 2012; Butz et al. 2014). Higher doses have been shown to increase risk of esophageal candidiasis. Randomized controlled trials of budesonide, given as a viscous suspension or nebulized, have shown histological remission rates of $27 \%-87 \%$ depending on the dose and method used. In a study of 20 children treated twice-daily with budesonide (in a slurry form using a sugar substitute to constitute the mixture), 
$80 \%$ had complete histological remission (Gupta et al. 2015). Other forms of budesonide have also been tried including an effervescent tablet $(83 \%$ histological response) and oral suspension (70\% histological response) (Miehlke et al. 2016; Moawad et al. 2016). Maintenance therapy is recommended for patients on swallowed steroid therapy. Half of the induction dose of topical steroid is commonly used as maintenance, however, further study is needed to understand the appropriate dose needed to keep patients in remission. Long-term administration of topical steroids appears to be safe and well tolerated (Moawad et al. 2016).

Esophageal dilation can be used to improve clinical symptoms in patients with narrowed esophagus or a stricture. Dilations are used mostly in adults. A barium swallow may be useful in guiding whether or not to proceed with dilation in patients who are not responding to pharmacologic or dietary therapy. Dilation does not change the histology of the disease. Dilation can be performed using 1 of 3 techniques: bougie, wire-guided, and controlled radial expansion balloons. The goal is to achieve an esophageal diameter of at least $15 \mathrm{~mm}$. Clinical efficacy seems to last 1-2 years (Moawad et al. 2013). Initial concerns of increased risk of dilations in EoE patients have been disproven. A meta-analysis reviewed 860 subjects and found a risk of hemorrhage of $0.1 \%$ and esophageal perforation of $0.3 \%$ (Moawad et al. 2013).

There have been multiple different biologic treatments that have been postulated to help in EoE. Omalizumab, an anti-IgE monoclonal antibody, was trialed in adolescent EoE subjects and showed decreased IgE levels in esophageal tissue, however, a prospective trial of omalizumab in EoE was ineffective in decreasing symptoms or esophageal eosinophilia (Loizou et al. 2015). Mepolizumab, an anti-IL-5 monoclonal antibody, showed promise in an open-label study of EoE patients. This study demonstrated a decrease in blood and esophageal eosinophilia as well as improved clinical outcomes with mepolizumab (Stein et al. 2006). A subsequent randomized, double-blind, placebo controlled (RDBPC) trial of mepolizumab in adult patients showed histological improvement, however, patients had minimal symptom improvement (Straumann et al. 2010). In a RDBPC trial of 59 pediatric subjects, mepolizumab decreased eosinophil counts in $89 \%$ of subjects. Interestingly, mast cell numbers also decreased in $77 \%$ of treated subjects, although, once again no symptomatic improvement was seen (Assa'ad et al. 2011; Otani et al. 2013). In the pediatric mepolizumab trial, subjects had mild symptom severity at baseline. Similarly, a large RDBPC trial of reslizumab, another anti-IL-5 monoclonal antibody, was conducted in 226 children and adolescents with EoE. This study found that treatment markedly decreased esophageal eosinophilia but symptomatic improvement was similar in both the active treatment and placebo groups (Spergel et al. 2012b). Most patients did not exhibit complete eosinophil resolution after therapy. The dissociation between esophageal eosinophil count improvement and symptom improvement suggests that other proinflammatory cells may contribute to EoE pathogenesis (Sriaroon and Ballow 2016).

QAX576, an anti-IL-13 monoclonal antibody, has been studied as a potential treatment for adults with EoE. A $60 \%$ reduction in esophageal eosinophils was seen with some symptomatic improvement including improved dysphagia. Genetic markers of EoE were modified with treatment including eotaxin-3, POSTN and mast cell markers. QAX576 continues to be studied (Rothenberg et al. 2015). Duplizumab is a monoclonal antibody that targets the IL- 4 receptor $\alpha$ subunit as well as the IL-13 receptor system. Duplizumab has been effective in asthma and atopic dermatitis (Spergel et al. 2012b; Boguniewicz 2017). An RDBPC trial is underway in adults with EoE (Spergel et al. 2012b). A CRTH2 antagonist, OC000459, was used to treat severe, refractory EoE in a small trial. In this trial there was a significant decrease in esophageal eosinophilic inflammation without complete resolution (Straumann et al. 2013).

\section{Prognosis}

EoE is a chronic and non-fatal disease. Endoscopic signs and histologic esophageal eosinophilia will persist if the condition is not adequately treated, and if treatment is stopped, the symptoms and signs (including histologic features) will recur in the majority of patients (Helou et al. 2008). The ultimate consequence of esophageal remodeling and fibrosis is stiffening and dysmotility. The natural history of untreated EoE in adults is progressive fibrostenosis. It has been found that esophageal rigidity may begin in childhood (O'Shea et al. 2017). While the esophageal signs and symptoms are chronic and progressive without treatment, there are no cases of EoE that have progressed 
to a systemic hyper-eosinophilic syndrome, or even spread beyond the esophagus to other areas of the GI tract. EoE does not increase cancer risk.

\section{Conclusion}

EoE is a chronic, immune-mediated disease, which is increasing in prevalence. A tremendous increase in research and therefore in the understanding of the pathogenesis and treatment of this disease process has occurred in the last few decades and continues. Emerging biologic therapies continue to be studied as our knowledge of pathogenesis of the disease process increases. In the mean-time, multiple treatment modalities including dietary therapy, topical corticosteroid therapy, and mechanical dilation continue to be used. The hope is that with better understanding of the disease process, targeted therapy will eventually make this an easier disease to manage.

\section{REFERENCES}

Aceves, S.S., Newbury, R.O., Dohil, M.A., Bastian, J.F., and Dohil, R. 2009. A symptom scoring tool for identifying pediatric patients with eosinophilic esophagitis and correlating symptoms with inflammation. Ann. Allergy Asthma Immunol. 103:401-406. PMID: 19927538. doi: 10.1016/S1081-1206(10) 60359-6.

Aceves, S.S., Newbury, R.O., Dohil, R., Schwimmer, J., and Bastian, J.F. 2007. Distinguishing eosinophilic esophagitis in pediatric patients: Clinical, endoscopic, and histologic features of an emerging disorder. J. Clin. Gastroenterol. 41:252-256. PMID: 17426462. doi: 10.1097/01.mcg.0000212639.52359.f1.

Akhondi, H. 2017. Diagnostic approaches and treatment of eosinophilic esophagitis. A review article. Ann. Med. Surg. 20:69-73. PMID: 28721213. doi: 10.1016/j.amsu.2017.06.022.

Alexander, E.S., Martin, L.J., Collins, M.H., Kottyan, L.C., Sucharew, H., He, H., Mukkada, V.A., Succop, P.A., Abonia, J.P., Foote, H., Eby, M.D., Grotjan, T.M., Greenler, A.J., Dellon, E.S., Demain, J.G., Furuta, G.T., Gurian, L.E., Harley, J.B., Hopp, R.J., Kagalwalla, A., Kaul, A., Nadeau, K.C., Noel, R.J., Putnam, P.E., von Tiehl, K.F., and Rothenberg, M.E. 2014. Twin and family studies reveal strong environmental and weaker genetic cues explaining heritability of eosinophilic esophagitis. J. Allergy Clin. Immunol. 134(5):1084-1092.e1. PMID: 25258143. doi: 10.1016/j.jaci.2014.07.021.
Alexander, J.A., Jung, K.W., Arora, A.S., Enders, F., Katzka, D.A., Kephardt, G.M., Kita, H., Kryzer, L.A., Romero, Y., Smyrk, T.C., and Talley, N.J. 2012. Swallowed fluticasone improves histologic but not symptomatic response of adults with eosinophilic esophagitis. Clin. Gastroenterol. Hepatol. 10:742749.e1. PMID: 22475741. doi: 10.1016/j.cgh.2012. 03.018 .

Alsalamah, M., Makhajia, M., Somers, G., Marcon, M., Hummel, D., and Upton, J. 2016. Corrigendum: Anaphylaxis to milk after elimination diet for eosinophilic gastrointestinal disease. Am. J. Gastroenterol. 111(7):1078. PMID: 27356845. doi: 10.1038/ajg. 2016.232.

Arias, A., González-Cervera, J., Tenias, J.M., and Lucendo, A.J. 2014. Efficacy of dietary interventions for inducing histologic remission in patients with eosinophilic esophagitis: A systematic review and meta-analysis. Gastroenterology. 146:1639-1648. PMID: 24534634. doi: 10.1053/j.gastro.2014.02.006.

Assa'ad, A.H., Gupta, S.K., Collins, M.H., Thomson, M., Heath, A.T., Smith, D.A., Perschy, T.L., Jurgensen, C.H., Ortega, H.G., and Aceves, S.S. 2011. An antibody against IL-5 reduces numbers of esophageal intraepithelial eosinophils in children with eosinophilic esophagitis. Gastroenterology. 141(5):15931604. PMID: 21835135. doi: 10.1053/j.gastro.2011. 07.044 .

Attwood, S.E., Smyrk, T.C., Demeester, T.R., and Jones, J.B. 1993. Esophageal eosinophilia with dysphagia. A distinct clinicopathologic syndrome. Dig. Dis. Sci. 38(1):109-116. PMID: 8420741. doi: 10.1007/ BF01296781.

Binkovitz, L.A., Lorenz, E.A., Di Lorenzo, C., and Kahwash, S. 2010. Pediatric eosinophilic esophagitis: Radiologic findings with pathologic correlation. Pediatr. Radiol. 40:714-719. PMID: 20020118. doi: 10.1007/s00247-009-1484-2.

Blanchard, C., Mingler, M.K., McBride, M., Putnam, P.E., Collins, M.H., Chang, G., Stringer, K., Abonia, J.P., Molkentin, J.D., and Rothenberg, M.E. 2008. Periostin facilitates eosinophil tissue infiltration in allergic lung and esophageal responses. Mucosal Immunol. 1:289-296. PMID: 19079190. doi: 10. 1038/mi.2008.15.

Blanchard, C., Wang, N., Stringer, K.F., Mishra, A., Fulkerson, P.C., Abonia, J.P., Jameson, S.C., Kirby, C., Konikoff, M.R., Collins, M.H., Cohen, M.B., Akers, R., Hogan, S.P., Assa'ad, A.H., Putnam, P.E., Aronow, B.J., and Rothenberg, M.E. 2006. Eotaxin-3 and a uniquely conserved gene-expression profile in 
eosinophilic esophagitis. J. Clin. Invest. 116:536-547. PMID: 16453027. doi: 10.1172/JCI26679.

Boguniewicz, M. 2017. Biologic therapy for atopic dermatitis: Moving beyond the practice parameter and guidelines. J. Allergy Clin. Immunol. Pract. 5(6):1477-1487. PMID: 29122151. doi: 10.1016/j. jaip.2017.08.031.

Bonis, P.A., and Furuta, G.T. 2017. Clinical manifestations and diagnosis of eosinophilic esophagitis. Edited by S. Grover. UpToDate, Waltham, MA, USA.

Butz, B.K., Wen, T., Gleich, G.J., Furuta, G.T., Spergel, J., King, E., Kramer, R.E., Collins, M.H., Stucke, E., Mangeot, C., Jackson, W.D., O'Gorman, M., Abonia, J.P., Pentiuk, S., Putnam, P.E., and Rothenberg, M.E. 2014. Efficacy, dose reduction, and resistance to high-dose fluticasone in patients with eosinophilic esophagitis. Gastroenterology. 147:324333.e5. PMID: 24768678. doi: 10.1053/j.gastro.2014. 04.019.

Clayton, F., Fang, J.C., Gleich, G.J., Lucendo, A.J., Olalla, J.M., Vinson, L.A., Lowichik, A., Chen, X., Emerson, L., Cox, K., O'Gorman, M.A., and Peterson, K.A. 2014. Eosinophilic esophagitis in adults is associated with IgG4 and not mediated by IgE. Gastroenterology. 147:602-609. PMID: 24907494. doi: 10.1053/j.gastro. 2014.05.036.

Dellon, E.S. 2014. Epidemiology of eosinophilic esophagitis. Gastroenterol. Clin. North Am. 43(2):201-218. PMID: 24813510. doi: 10.1016/j.gtc.2014.02.002.

Dellon, E.S., Gibbs, W.B., Fritchie, K.J., Rubinas, T.C., Wilson, L.A., Woosley, J.T., and Shaheen, N.J. 2009. Clinical, endoscopic, and histologic findings distinguish eosinophilic esophagitis from gastroesophageal reflux disease. Clin. Gastroenterol. Hepatol. 7:13051313. PMID: 19733260. doi: 10.1016/j.cgh.2009. 08.030.

Dellon, E.S., Gonsalves, N., Hirano, I., Furuta, G.T., Liacouras, C.A., and Katzka, D.A. 2013a. ACG clinical guideline: Evidenced based approach to the diagnosis and management of esophageal eosinophilia and eosinophilic esophagitis (EOE). Am. J. Gastroenterol. 108(5):679-692. PMID: 23567357. doi: 10.1038/ajg.2013.71.

Dellon, E.S., Jensen, E.T., Martin, C.F., Shaheen, N.J., and Kappelman, M.D. 2014. Prevalence of eosinophilic esophagitis in the United States. Clin. Gastroenterol. Hepatol. 12(4):589-596.e1. PMID: 24035773. doi: 10.1016/j.cgh.2013.09.008.

Dellon, E.S, Peery, A.F., Shaheen, N.J., Morgan, D.R., Hurrell, J.M., Lash, R.H., and Genta, R.M. 2011. Inverse association of esophageal eosinophilia with
Helicobacter pylori based on analysis of a US pathology database. Gastroenterology. 141(5):1586-1592. PMID: 21762663. doi: 10.1053/j.gastro.2011.06.081.

Dellon, E.S., Speck, O., Woodward, K., Gebhart, J.H., Madanick, R.D., Levinson, S., Fritchie, K.J., Woosley, J.T., and Shaheen, N.J. 2013b. Clinical and endoscopic characteristics do not reliably differentiate PPIresponsive esophageal eosinophilia and eosinophilic esophagitis in patients undergoing upper endoscopy: A prospective cohort study. Am. J. Gastroenterol. 108(12):1854-1860. PMID: 24145677. doi: 10.1038/ ajg.2013.363.

Erwin, E.A., James, H.R., Gutekunst, H.M., Russo, J.M., Kelleher, K.J., and Platts-Mills, T.A. 2010. Serum IgE measurement and detection of food allergy in pediatric patients with eosinophilic esophagitis. Ann. Allergy Asthma Immunol. 104:496-502. PMID: 20568382. doi: 10.1016/j.anai.2010.03.018.

Franciosi, J.P., Tam, V., Liacouras, C.A., and Spergel, J.M. 2009. A case-control study of sociodemographic and geographic characteristics of 335 children with eosinophilic esophagitis. Clin. Gastroenterol. Hepatol. 7(4):415-419. PMID: 19118642. doi: 10. 1016/j.cgh.2008.10.006.

Furuta, G.T., Kagalwalla, A.F., Lee, J.J., Alumkal, P., Maybruck, B.T., Fillon, S., Masterson, J.C., Ochkur, S., Protheroe, C., Moore, W., Pan, Z., Amsden, K., Robinson, Z., Capocelli, K., Mukkada, V., Atkins, D., Fleischer, D., Hosford, L., Kwatia, M.A., Schroeder, S., Kelly, C., Lovell, M., Melin-Aldana, H., and Ackerman, S.J. 2013. The oesophageal string test: A novel, minimally invasive method measures mucosal inflammation in eosinophilic oesophagitis. Gut. 62(10):1395-1405. PMID: 22895393. doi: 10.1136/ gutjnl-2012-303171.

Giriens, B., Yan, P., Safroneeva, E., Zwahlen, M., Reinhard, A., Nydegger, A., Vavricka, S., Sempoux, C., Straumann, A., and Schoepfer, A.M. 2015. Escalating incidence of eosinophilic esophagitis in Canton of Vaud, Switzerland, 1993-2013: A population-based study. Allergy. 70(12):1633-1639. PMID: 26304142. doi: 10.1111/all.12733.

Gudbjartsson, D.F., Bjornsdottir, U.S., Halapi, E., Helgadottir, A., Sulem, P., Jonsdottir, G.M., Thorleifsson, G., Helgadottir, H., Steinthorsdottir, V., Stefansson, H., Williams, C., Hui, J., Beilby, J., Warrington, N.M., James, A., Palmer, L.J., Koppelman, G.H., Heinzmann, A., Krueger, M., Boezen, H.M., Wheatley, A., Altmuller, J., Shin, H.D., Uh, S.T., Cheong, H.S., Jonsdottir, B., Gislason, D., Park, C.S., Rasmussen, L.M., Porsbjerg, C., 
Hansen, J.W., Backer, V., Werge, T., Janson, C., Jönsson, U.B., Ng, M.C., Chan, J., So, W.Y., Ma, R., Shah, S.H., Granger, C.B., Quyyumi, A.A., Levey, A.I., Vaccarino, V., Reilly, M.P., Rader, D.J., Williams, M.J., van Rij, A.M., Jones, G.T., Trabetti, E., Malerba, G., Pignatti, P.F., Boner, A., Pescollderungg, L., Girelli, D., Olivieri, O., Martinelli, N., Ludviksson, B.R., Ludviksdottir, D., Eyjolfsson, G.I., Arnar, D., Thorgeirsson, G., Deichmann, K., Thompson, P.J., Wjst, M., Hall, I.P., Postma, D.S., Gislason, T., Gulcher, J., Kong, A., Jonsdottir, I., Thorsteinsdottir, U., and Stefansson, K. 2009. Sequence variants affecting eosinophil numbers associate with asthma and myocardial infarction. Nat. Genet. 41:342-347. PMID: 19198610. doi: 10.1038/ng.323.

Gupta, S.K., Vitanza, J.M., and Collins, M.H. 2015. Efficacy and safety of oral budesonide suspension in pediatric patients with eosinophilic esophagitis. Clin. Gastroenterol. Hepatol. 13:66-76.e3. PMID: 24907502. doi: 10.1016/j.cgh.2014.05.021.

Harris, J.K., Fang, R., Wagner, B.D., Choe, H.N., Kelly, C.J., Schroeder, S., Moore, W., Stevens, M.J., Yeckes, A., Amsden, K., Kagalwalla, A.F., Zalewski, A., Hirano, I., Gonsalves, N., Henry, L.N., Masterson, J.C., Robertson, C.E., Leung, D.Y., Pace, N.R., Ackerman, S.J., Furuta, G.T., and Fillon, S.A. 2015. Esophageal microbiome in eosinophilic esophagitis. PLoS ONE. 10(5):e0128346. PMID: 26020633. doi: 10.1371/journal.pone.0128346.

Helou, E.F., Simonson, J., and Arora, A.S. 2008. 3-yr-follow-up of topical corticosteroid treatment for eosinophilic esophagitis in adults. Am. J. Gastroenterol. 103(9):2194-2199. PMID: 18637093. doi: 10.1111/j.1572-0241.2008.01989.x.

Henderson, C.J., Abonia, J.P., King, E.C., Putnam, P.E., Collins, M.H., Franciosi, J.P., and Rothenberg, M.E. 2012. Comparative dietary therapy effectiveness in remission of pediatric eosinophilic esophagitis. J. Allergy Clin. Immunol. 129:1570-1578. PMID: 22541246. doi: 10.1016/j.jaci.2012.03.023.

Hill, D.A., Shuker, M., Cianferoni, A., Wong, T., Ruchelli, E., Spergel, J.M., and Brown-Whitehorn, T.F. 2015. The development of IgE-mediated immediate hypersensitivity after the diagnosis of eosinophilic esophagitis to the same food. J. Allergy Clin. Immunol. Pract. 3(1):123-124. PMID: 25577634. doi: 10.1016/j.jaip.2014.08.005.

Hruz, P., Straumann, A., Bussmann, C., Heer, P., Simon, H.U., Zwahlen, M., Beglinger, C., Schoepfer, A.M., and Swiss EoE study group. 2011. Escalating incidence of eosinophilic esophagitis: A 20-year prospective, population-based study in Olten County, Switzerland. J. Allergy Clin. Immunol. 128(6):1349-1350.e5. PMID: 22019091. doi: 10.1016/ j.jaci.2011.09.013.

Hurrell, J.M., Genta, R.M., and Dellon, E.S. 2012. Prevalence of esophageal eosinophilia varies by climate zone in the United States. Am. J. Gastroenterol. 107(5):698-706. PMID: 22310220. doi: 10.1038/ ajg.2012.6.

Ishihara, S., Kinoshita, Y., and Schoepfer, A. 2016. Eosinophilic esophagitis, eosinophilic gastroenteritis, and eosinophilic colitis: Common mechanisms and differences between East and West. Inflamm. Intest. Dis. 1:63-69. doi: 10.1159/000445131.

Jensen, E.T., Hoffman, K., Shaheen, N.J., Genta, R.M., and Dellon, E.S. 2014. Esophageal eosinophilia is increased in rural areas with low population density: Results from a national pathology database. Am. J. Gastroenterol. 109(5):668-675. PMID: 24667575. doi: 10.1038/ajg.2014.47.

Jensen, E.T., Kappelman, M.D., Kim, H.P., RingelKulka, T., and Dellon, E.S. 2013. Early life exposures as risk factors for pediatric eosinophilic esophagitis. J. Pediatr. Gastroenterol. Nutr. 57(1):67-71. PMID: 23518485. doi: 10.1097/MPG.0b013e318290d15a.

Kagalwalla, A.F., Amsden, K., Shah, A., Ritz, S., Manuel-Rubio, M., Dunne, K., Nelson, S.P., Wershil, B.K., and Melin-Aldana, H. 2012. Cow's milk elimination: A novel dietary approach to treat eosinophilic esophagitis. J. Pediatr. Gastroenterol. Nutr. 55:711716. PMID: 22820121. doi: 10.1097/MPG.0b013e 318268 da40.

Kagalwalla, A.F., Sentongo, T.A., Ritz, S., Hess, T., Nelson, S.P., Emerick, K.M., Melin-Aldana, H., and Li, B.U. 2006. Effect of six-food elimination diet on clinical and histologic outcomes in eosinophilic esophagitis. Clin. Gastroenterol. Hepatol. 4:10971102. PMID: 16860614. doi: 10.1016/j.cgh.2006. 05.026.

Kagalwalla, A.F., Shah, A., Li, B.U., Sentongo, T.A., Ritz, S., Manuel-Rubio, M., Jacques, K., Wang, D., Melin-Aldana, H., and Nelson, S.P. 2011. Identification of specific foods responsible for inflammation in children with eosinophilic esophagitis successfully treated with empiric elimination diet. J. Pediatr. Gastroenterol. Nutr. 53(2):145-149. PMID: 21788754. doi: 10.1097/MPG.0b013e31 $821 \mathrm{cf} 503$.

Kagalwalla, A.F., Wechsler, J.B., Amsden, K., Schwartz, S., Makhija, M., Olive, A., Davis, C.M., ManuelRubio, M., Marcus, S., Shaykin, R., Sulkowski, M., 
Johnson, K., Ross, J.N., Riffle, M.E., Groetch, M., Melin-Aldana, H., Schady, D., Palac, H., Kim, K.A., Wershil, B.K., Collins, M.H., and Chehade, M. 2017. Efficacy of a 4-food elimination diet for children with eosinophilic esophagitis. Clin. Gastroenterol. Hepatol. 15(11):1698-1707.e7. PMID: 28603055. doi: 10.1016/ j.cgh.2017.05.048.

Kapel, R.C., Miller, J.K., Torres, C., Aksoy, S., Lash, R., and Katzka, D.A. 2008. Eosinophilic esophagitis: A prevalent disease in the United States that affects all age groups. Gastroenterology. 134:1316-1321. PMID: 18471509. doi: 10.1053/j.gastro.2008.02.016.

Katzka, D.A., Geno, D.M., Ravi, A., Smyrk, T.C., LaoSirieix, P., Miremadi, A., Debiram, I., O’Donovan, M., Kita, H., Kephart, G.M., Kryzer, L.A., Camilleri, M., Alexander, J.A., and Fitzgerald, R.C. 2015. Accuracy, safety, and tolerability of tissue collection by Cytosponge vs endoscopy for evaluation of eosinophilic esophagitis. Clin. Gastroenterol. Hepatol. 13(1):77-83.e2. PMID: 24997328. doi: 10.1016/j.cgh. 2014.06.026.

Kedika, R.R., Souza, R.F., and Spechler, S.J. 2009. Potential anti-inflammatory effects of proton pump inhibitors: A review and discussion of the clinical implications. Dig. Dis. Sci. 54:2312-2317. PMID: 19714466. doi: 10.1007/s10620-009-0951-9.

Konikoff, M.R., Noel, R.J., Blanchard, C., Kirby, C., Jameson, S.C., Buckmeier, B.K., Akers, R., Cohen, M.B., Collins, M.H., Assa'ad, A.H., Aceves, S.S., Putnam, P.E., and Rothenberg, M.E. 2006. A randomized, double-blind, placebo-controlled trial of fluticasone propionate for pediatric eosinophilic esophagitis. Gastroenterology. 131:1381-1391. PMID: 17101314. doi: 10.1053/j.gastro.2006.08.033.

Kruszewski, P.G., Russo, J.M., Franciosis, J.P., Varni, J.W., Platts-Mills, T.A., and Erwin, E.A. 2016. Prospective, comparative effectiveness trial of cow's milk elimination and swallowed fluticasone for pediatric eosinophilic esophagitis. Dis. Esophagus. 29:377-384. PMID: 25721813. doi: 10.1111/dote. 12339.

Landres, R.T., Kuster, G.G., and Strum, W.B. 1978. Eosinophilic esophagitis in a patient with vigorous achalasia. Gastroenterology. 74(6):1298-1301. PMID: 648822.

Leung, J., Virk Hundal, N., Katz, A.J., Shreffler, W.G., Yuan, Q., Butterworth, C.A., and Hesterberg, P.E. 2013. Tolerance of baked milk in patients with cow's milk-mediated eosinophilic esophagitis. J. Allergy Clin. Immunol. 132(5):1215-1216.e1. PMID: 24084076. doi: $10.1016 /$ j.jaci.2013.08.017.
Liacouras, C.A., Furuta, G.T., Hirano, I., Atkins, D., Attwood, S.E., Bonis, P.A., Burks, A.W., Chehade, M., Collins, M.H., Dellon, E.S., Dohil, R., Falk, G.W., Gonsalves, N., Gupta, S.K., Katzka, D.A., Lucendo, A.J., Markowitz, J.E., Noel, R.J., Odze, R.D., Putnam, P.E., Richter, J.E., Romero, Y., Ruchelli, E., Sampson, H.A., Schoepfer, A., Shaheen, N.J., Sicherer, S.H., Spechler, S., Spergel, J.M., Straumann, A., Wershil, B.K., Rothenberg, M.E., and Aceves, S.S. 2011. Eosinophilic esophagitis: Updated consensus recommendations for children and adults. J. Allergy Clin. Immunol. 128(1):3-20.e6. PMID: 21477849. doi: 10.1016/j.jaci.2011.02.040.

Litosh, VA, Rochman, M., Rymer, J.K., Porollo, A., Kottyan, L.C., and Rothenberg, M.E. 2017. Calpain14 and its association with eosinophilic esophagitis. J. Allergy Clin. Immunol. 139(6):1762-1771.e7. PMID: 28131390. doi: 10.1016/j.jaci.2016.09.027.

Loizou, D., Enav, B., Komlodi-Pasztor, E., Hider, P., Kim-Chang, J., Noonan, L., Taber, T., Kaushal, S., Limgala, R., Brown, M., Gupta, R., Balba, N., GokerAlpan, O., Khojah, A., and Alpan, O. 2015. A pilot study of omalizumab in eosinophilic esophagitis. PLoS ONE. 10:e0113483. PMID: 25789989. doi: 10.1371/journal.pone.0113483.

Mackenzie, S.H., Go, M., Chadwick, B., Thomas, K., Fang, J., Kuwada, S., Lamphier, S., Hilden, K., and Peterson, K. 2008. Eosinophilic oesophagitis in patients presenting with dysphagia-A prospective analysis. Aliment. Pharmacol. Ther. 28(9):11401146. PMID: 18624788. doi: 10.1111/j.1365-2036. 2008.03795.x.

Markowitz, J.E., Spergel, J.M., Ruchelli, E., and Liacouras, C.A. 2003. Elemental diet is an effective treatment for eosinophilic esophagitis in children and adolescents. Am. J. Gastroenterol. 98:777-782. PMID: 12738455. doi: 10.1111/j.1572-0241.2003. 07390.x.

Masuoka, M., Shirasishi, H., Ohta, S., Suzuki, S., Arima, K., Aoki, S., Toda, S., Inagaki, N., Kurihara, Y., Hayashida, S., Takeuchi, S., Koike, K., Ono, J., Noshiro, H., Furue, M., Conway, S.J., Narisawa, Y., and Izuhara, K. 2012. Periostin promotes chronic allergic inflammation in response to Th2 cytokines. J. Clin. Invest. 122:2590-2600. PMID: 22684102. doi: 10.1172/JCI58978.

Merwat, S.N., and Spechler, S.J. 2009. Might the use of acid-suppressive medications predispose to the development of eosinophilic esophagitis? Am. J. Gastroenterol. 104(8):1897-1902. PMID: 19661930. doi: 10.1038/ajg.2009.87. 
Miehlke, S., Hruz, P., Vieth, M., Bussmann, C., von Arnim, U., Bajbouj, M., Schlag, C., Madisch, A., Fibbe, C., Wittenburg, H., Allescher, H.D., Reinshagen, M., Schubert, S., Tack, J., Müller, M., Krummenerl, P., Arts, J., Mueller, R., Dilger, K., Greinwald, R., and Straumann, A. 2016. A randomised, double-blind trial comparing budesonide formulations and dosages for short-term treatment of eosinophilic oesophagitis. Gut. 65:390-399. PMID: 25792708. doi: 10.1136/gutjnl-2014-308815.

Mishra, A., Hogan, S.P., Brandt, E.B., and Rothenberg, M.E. 2001. An etiological role for aeroallergens and eosinophils in experimental esophagitis. J. Clin. Invest. 107:83-90. PMID: 11134183. doi: 10.1172/ JCI10224.

Moawad, F.J., Cheatham, J.G., and DeZee, K.J. 2013. Meta-analysis: The safety and efficacy of dilation in eosinophilic oesophagitis. Aliment. Pharmacol. Ther. 38:713-720. PMID: 23915046. doi: 10.1111/apt. 12438.

Moawad, F.J., Cheng, E., Schoepfer, A., Al-Haddad, S., Bellizzi, A.M., Dawson, H., El-Zimaity, H., Guindi, M., Penagini, R., Safrooneva, E., and Chehade, M. 2016. Eosinophilic esophagitis: Current perspectives from diagnosis to management. Ann. N.Y. Acad. Sci. 1380:204-217. PMID: 27467185. doi: 10.1111/ nyas. 13164 .

Molina-Infante, J., and Katzka, D.A. 2014. Protonpump inhibitor-responsive esophageal eosinophilia. Curr. Opin. Gastroenterol. 30(4):428-433. PMID: 24837227. doi: 10.1097/MOG.0000000000000080.

Molina-Infante, J., Ferrando-Lamana, L., Ripoll, C., Hernandez-Alonso, M., Mateos, J.M., FernandezBermejo, M., Dueñas, C., Fernandez-Gonzalez, N., Quintana, E.M., and Gonzalez-Nuñez, M.A. 2011. Esophageal eosinophilic infiltration responds to proton pump inhibition in most adults. Clin. Gastroenterol. Hepatol. 9:110-117. PMID: 20920599. doi: 10.1016/j.cgh.2010.09.019.

Mukkada, V.A., Haas, A., Maune, N.C., Capocelli, K.E., Henry, M., Gilman, N., Petersburg, S., Moore, W., Lovell, M.A., Fleischer, D.M., Furuta, G.T., and Atkins, D. 2010. Feeding dysfunction in children with eosinophilic gastrointestinal diseases. Pediatrics. 126(3):e672-e677. PMID: 20696733. doi: 10.1542/ peds.2009-2227.

Mullin, J.M., Valenzano, M.C., Whitby, M., Lurie, D., Schmidt, J.D., Jain, V., Tully, O., Kearney, K., Lazowick, D., Mercogliano, G., and Thornton, J.J. 2008. Esomeprazole induces upper gastrointestinal tract transmucosal permeability increase. Aliment.
Pharmacol. Ther. 28(11-12):1317-1325. PMID: 18684245. doi: 10.1111/j.1365-2036.2008.03824.x.

Noel, R.J., Putnam, P.E., and Rothenberg, M.E. 2004. Eosinophilic esophagitis. N. Engl. J. Med. 351(9):940-941. PMID: 15329438. doi: 10.1056/ NEJM200408263510924.

Okada, H., Kuhn, C., Feillet, H., and Bach, J.F. 2010. The 'hygiene hypothesis' for autoimmune and allergic diseases: An update. Clin. Exp. Immunol. 160(1):1-9. PMID: 20415844. doi: 10.1111/j.1365-2249.2010. 04139.x.

O’Regan, G.M., Sandilands, A., McLean, W.H., and Irvine, A.D. 2008. Filaggrin in atopic dermatitis. J. Allergy Clin. Immunol. 122:689-693. PMID: 18774165. doi: 10.1016/j.jaci.2008.08.002.

O'Shea, K.M., Aceves, S.S., Dellon, E.S., Gupta, S.K., Spergel, J.M., Furuta, G.T., and Rothenberg, M.E. 2017. Pathophysiology of eosinophilic esophagitis. Gastroenterology. PMID: 28757265. doi: 10.1053/j. gastro.2017.06.065.

Otani, I.M., Anilkumar, A.A., Newbury, R.O., Bhagat, M., Beppu, L.Y., Dohil, R., Broide, D.H., and Aceves, S.S. 2013. Anti-IL-5 therapy reduces mast cell and IL-9 cell numbers in pediatric patients with eosinophilic esophagitis. J. Allergy Clin. Immunol. 131:1576-1582.e2. PMID: 23623266. doi: 10.1016/j. jaci.2013.02.042.

Pentiuk, S., Putnam, P.E., Collins, M.H., and Rothenberg, M.E. 2009. Dissociation between symptoms and histological severity in pediatric eosinophilic esophagitis. J. Pediatr. Gastroenterol. Nutr. 48:152-160. PMID: 19179876. doi: 10.1097/MPG. 0b013e31817f0197.

Peterson, K.A., Byrne, K.R., Vinson, L.A., Ying, J., Boynton, K.K., Fang, J.C., Gleich, G.J., Adler, D.G., and Clayton, F. 2013. Elemental diet induces histologic response in adult eosinophilic esophagitis. Am. J. Gastroenterol. 108:759-766. PMID: 23381017. doi: 10.1038/ajg.2012.468.

Philpott, H., Nandurkar, S., Royce, S.G., Thien, F., and Gibson, P.R. 2016. Allergy tests do not predict food triggers in adult patients with eosinophilic oesophagitis. A comprehensive prospective study using five modalities. Aliment. Pharmacol. Ther. 44(3):223233. PMID: 27247257. doi: 10.1111/apt.13676.

Prasad, G.A., Alexander, J.A., Schleck, C.D., Zinsmeister, A.R., Smyrk, T.C., Elias, R.M., Locke, G.R., III, and Talley, N.J. 2009. Epidemiology of eosinophilic esophagitis over three decades in Olmsted County, Minnesota. Clin. Gastroenterol. Hepatol. 7(10):10551061. PMID: 19577011. doi: 10.1016/j.cgh.2009.06.023. 
Prasad, G.A., Talley, N.J., Romero, Y., Arora, A.S., Kryzer, L.A., Smyrk, T.C., and Alexander, J.A. 2007. Prevalence and predictive factors of eosinophilic esophagitis in patients presenting with dysphagia: A prospective study. Am. J. Gastroenterol. 102(12):2627-2632. PMID: 17764492. doi: 10.1111/ j.1572-0241.2007.01512.x.

Radano, M.C., Yan, Q., Katz, A., Fleming, J.T., Kubala, S., Shreffler, W., and Keet, C.A. 2014. Cesarean section and antibiotic use found to be associated with eosinophilic esophagitis. J. Allergy Clin. Immunol. Pract. 2:475-477.e1. PMID: 25017541. doi: 10.1016/j. jaip.2014.02.018.

Rayapudi, M., Mavi, P., Zhu, X., Pandey, A.K., Abonia, J.P., Rothenberg, M.E., and Mishra, A. 2010. Indoor insect allergens are potent inducers of experimental eosinophilic esophagitis in mice. J. Leukoc. Biol. 88:337-346. PMID: 20413729. doi: 10.1189/jlb. 0110025.

Ricker, J., McNear, S., Cassidy, T., Plott, E., Arnold, H., Kendall, B., and Franklin, K. 2011. Routine screening for eosinophilic esophagitis in patients presenting with dysphagia. Therap. Adv. Gastroenterol. 4(1):27-35. PMID: 21317992. doi: 10.1177/175628 3X10384172.

Rochman, M., Travers, J., Miracle, C.E., Bedard, M.C., Wen, T., Azouz, N.P., Caldwell, J.M., Kc, K., Sherrill, J.D., Davis, B.P., Rymer, J.K., Kaufman, K.M., Aronow, B.J., and Rothenberg, M.E. 2017. Profound loss of esophageal tissue differentiation in patients with eosinophilic esophagitis. J. Allergy Clin. Immunol. 140(3):738-749.e3. PMID: 28104354. doi: 10.1016/j.jaci.2016.11.042.

Rothenberg, M.E., Spergel, J.M., Sherrill, J.D., Annaiah, K., Martin, L.J., Cianferoni, A., Gober, L., Kim, C., Glessner, J., Frackelton, E., Thomas, K., Blanchard, C., Liacouras, C., Verma, R., Aceves, S., Collins, M.H., Brown-Whitehorn, T., Putnam, P.E., Franciosi, J.P., Chiavacci, R.M., Grant, S.F., Abonia, J.P., Sleiman, P.M., and Hakonarson, H. 2010. Common variants at $5 \mathrm{q} 22$ associate with pediatric eosinophilic esophagitis. Nat. Genet. 42(4):289-291. PMID: 20208534. doi: 10.1038/ng.547.

Rothenberg, M.E., Wen, T., Greenberg, A., Alpan, O., Enav, B., Hirano, I., Nadeau, K., Kaiser, S., Peters, T., Perez, A., Jones, I., Arm, J.P., Strieter, R.M., Sabo, R., and Gunawardena, K.A. 2015. Intravenous antiIL-13 mAb QAX576 for the treatment of eosinophilic esophagitis. J. Allergy Clin. Immunol. 135:500-507. PMID: 25226850. doi: 10.1016/j.jaci.2014.07.049.
Roy-Ghanta, S., Larosa, D.F., and Katzka, D.A. 2008. Atopic characteristics of adult patients with eosinophilic esophagitis. Clin. Gastroenterol. Hepatol. 6:531-535. PMID: 18304887. doi: 10.1016/j.cgh. 2007.12.045.

Safroneeva, E., Straumann, A., Coslovsky, M., Zwahlen, M., Kuehni, C.E., Panczak, R., Haas, N.A., Alexander, J.A., Dellon, E.S., Gonsalves, N., Hirano, I., Leung, J., Bussmann, C., Collins, M.H., Newbury, R.O., De Petris, G., Smyrk, T.C., Woosley, J.T., Yan, P., Yang, G.Y., Romero, Y., Katzka, D.A., Furuta, G.T., Gupta, S.K., Aceves, S.S., Chehade, M., Spergel, J.M., Schoepfer, A.M., and International Eosinophilic Esophagitis Activity Index Study Group. 2016. Symptoms have modest accuracy in detecting endoscopic and histologic remission in adults with eosinophilic esophagitis. Gastroenterology. 150:581-590.e4. PMID: 26584601. doi: 10.1053/j.gastro.2015.11.004.

Shah, A., Kagalwalla, A.F., Gonsalves, N., MelinAldana, H., Li, B.U., and Hirano, I. 2009. Histopathologic variability in children with eosinophilic esophagitis. Am. J. Gastroenterol. 104:716721. PMID: 19209168. doi: 10.1038/ajg.2008.117.

Sherrill, J.D., Kc, K., Wu, D., Djukic, Z., Caldwell, J.M., Stucke, E.M., Kemme, K.A., Costello, M.S., Mingler, M.K., Blanchard, C., Collins, M.H., Abonia, J.P., Putnam, P.E., Dellon, E.S., Orlando, R.C., Hogan, S.P., and Rothenberg, M.E. 2014. Desmoglein-1 regulates esophageal epithelial barrier function and immune responses in eosinophilic esophagitis. Mucosal Immunol. 7:718-729. PMID: 24220297. doi: 10.1038/mi.2013.90.

Soller, L., Mill, C., Avinashi, V., Teohm, T., and Chan, E.S. 2017. Development of anaphylactic cow's milk allergy following cow's milk elimination for eosinophilic esophagitis in a teenager. J. Allergy Clin. Immunol. Pract. 5(5):1413-1414. PMID: 28389301. doi: 10.1016/j.jaip.2017.02.021.

Sonnenberg, A., Dellon, E.S., Turner, K.O., and Genta, R.M. 2017. The influence of Helicobacter pylori on the ethnic distribution of esophageal eosinophilia. Helicobacter. 22(3):e12370. PMID: 28029200. doi: 10.1111/hel.12370.

Spergel, J.M., Book, W.M., Mays, E., Song, L., Shah, S.S., Talley, N.J., and Bonis, P.A. 2011. Variation in prevalence, diagnostic criteria, and initial management options for eosinophilic gastrointestinal diseases in the United States. J. Pediatr. Gastroenterol. Nutr. 52(3):300-306. PMID: 21057327. doi: 10.1097/MPG. 0b013e3181eb5a9f. 
Spergel, J.M., Brown-Whitehorn, T.F., Beausoleil, J.L., Franciosi, J., Shuker, M., Verma, R., and Liacouras, C.A. 2009. 14 years of eosinophilic esophagitis: Clinical features and prognosis. J. Pediatr. Gastroenterol. Nutr. 48:30-36. PMID: 19172120. doi: 10.1097/MPG.0b013e3181788282.

Spergel, J.M., Brown-Whitehorn, T.F., Beausoleil, J.L., Shuker, M., and Liacouras, C.A. 2007. Predictive values for skin prick test and atopy patch test for eosinophilic esophagitis. J. Allergy Clin. Immunol. 1 19:509-511. PMID: 17291865. doi: 10.1016/j.jaci. 2006.11.016.

Spergel, J.M., Brown-Whitehorn, T.F., Cianferoni, A., Shuker, M., Wang, M.L., Verma, R., and Liacouras, C.A. 2012a. Identification of causative foods in children with eosinophilic esophagitis treated with an elimination diet. J. Allergy Clin. Immunol. 130(2):461-467.e5. PMID: 22743304. doi: 10.1016/j. jaci.2012.05.021.

Spergel, J.M., Rothenberg, M.E., Collins, M.H., Furuta, G.T., Markowitz, J.E., Fuchs, G., III, O’Gorman, M.A., Abonia, J.P., Young, J., Henkel, T., Wilkins, H.J., and Liacouras, C.A. 2012b. Reslizumab in children and adolescents with eosinophilic esophagitis: Results of a double-blind, randomized, placebocontrolled trial. J. Allergy Clin. Immunol. 129:456463.e3. PMID: 22206777. doi: 10.1016/j.jaci.2011. 11.044 .

Sperry, S.L., Crockett, S.D., Miller, C.B., Shaheen, N.J., and Dellon, E.S. 2011. Esophageal foreignbody impactions: Epidemiology, time trends, and the impact of the increasing prevalence of eosinophilic esophagitis. Gastrointest. Endosc. 74(5): 985-991. PMID: 21889135. doi: 10.1016/j.gie. 2011.06.029.

Sriaroon, P., and Ballow, M. 2016. Biological modulators in eosinophilic diseases. Clin. Rev. Allerg. Immunol. 50:252-272. PMID: 25129490. doi: 10. 1007/s12016-014-8444-9.

Stein, M.L., Collins, M.H., Villaneuva, J.M., Kushner, J.P., Putnam, P.E., Buckmeier, B.K., Filipovich, A.H., Assa'ad, A.H., and Rothenberg, M.E. 2006. Anti-IL-5 (mepolizumab) therapy for eosinophilic esophagitis.
J. Allergy Clin. Immunol. 118(6):1312-1319. PMID: 17157662. doi: 10.1016/j.jaci.2006.09.007.

Straumann, A., Conus, S., Grzonka, P., Kita, H., Kephart, G., Bussmann, C., Beglinger, C., Smith, D.A., Patel, J., Byrne, M., and Simon, H.U. 2010. Anti-interleukin-5 antibody treatment (mepolizu$\mathrm{mab}$ ) in active eosinophilic oesophagitis: A randomised, placebo-controlled, double-blind trial. Gut. 59:21-30. PMID: 19828470. doi: 10.1136/gut.2009. 178558.

Straumann, A., Hoesli, S., Bussmann, C., Stuck, M., Perkins, M., Collins, L.P., Payton, M., Pettipher, R., Hunter, M., Steiner, J., and Simon, H.U. 2013. Antieosinophil activity and clinical efficacy of the CRTH2 antagonist OC000459 in eosinophilic esophagitis. Allergy. 68:375-385. PMID: 23379537. doi: $10.1111 /$ all.12096.

Sugnanam, K.K., Collins, J.T., Smith, P.K., Connor, F., Lewindon, P., Cleghorn, G., and Withers, G. 2007. Dichotomy of food and inhalant allergen sensitization in eosinophilic esophagitis. Allergy. 62:1257-1260. PMID: 17711545. doi: 10.1111/j.1398-9995.2007. 01454.x.

Veerappan, G.R., Perry, J.L., Duncan, T.J., Baker, T.P., Maydonovitch, C., Lake, J.M., Wong, R.K., and Osgard, E.M. 2009. Prevalence of eosinophilic esophagitis in an adult population undergoing upper endoscopy: A prospective study. Clin. Gastroenterol. Hepatol. 7(4):420-426.e2. PMID: 19162236. doi: 10. 1016/j.cgh.2008.10.009.

von Arnim, U., Wex, T., Link, A., Messerschmidt, M., Venerito, M., Miehlke, S., and Malfertheiner, P. 2016. Helicobacter pylori infection is associated with a reduced risk of developing eosinophilic oesophagitis. Aliment. Pharmacol. Ther. 43:825-830. PMID: 26898731. doi: 10.1111/apt.13560.

Wen, T., Stucke, E.M., Grotjan, T.M., Kemme, K.A., Abonia, J.P., Putnam, P.E., Franciosi, J.P., Garza, J.M., Kaul, A., King, E.C., Collins, M.H., Kushner, J.P., and Rothenberg, M.E. 2013. Molecular diagnosis of eosinophilic esophagitis by gene expression profiling. Gastroenterology. 145:1289-1299. PMID: 23978633. doi: 10.1053/j.gastro.2013.08.046. 